\title{
Caracterização dos fatores de risco e ocorrência de óbito em recém-nascidos com diagnóstico de sepse neonatal em uma Unidade de Terapia Intensiva Neonatal
}

\author{
Characterization of risk factors and occurrence of death in newborns diagnosed with neonatal \\ sepsis in a Neonatal Intensive Care Unit
}

Caracterización de factores de riesgo y ocurrencia de muerte en recién-nacidos con diagnóstico de sepsis neonatal en una Unidad de Cuidados Intensivos Neonatales

Recebido: 19/01/2022 | Revisado: 29/01/2022 | Aceito: 09/02/2022 | Publicado: 11/02/2022

\author{
Cinara Rejane Viana Oliveira \\ ORCID: https://orcid.org/0000-0002-4835-2481 \\ Universidade do Estado da Bahia, Brasil \\ E-mail: cinararejane26@gmail.com \\ Ney Cristian Amaral Boa Sorte \\ ORCID: https://orcid.org/0000-0001-7068-3319 \\ Universidade do Estado da Bahia, Brasil \\ E-mail: nboasorte@uneb.br
}

\begin{abstract}
Resumo
A sepse neonatal é uma das principais causas de morte de recém-nascidos. O conhecimento prévio dos fatores de risco são fundamentais para prevenir a morbimortalidade. Este estudo tem como objetivo caracterizar os fatores de risco observados e sua relação com a ocorrência de óbito em recém-nascidos com diagnóstico de sepse. Realizou-se um estudo transversal com análise de 712 participantes internados no período de setembro de 2018 a junho de 2020 . Foram incluídos 410 neonatos sendo de maior proporção os do sexo masculinos, nascidos com via de parto artificial e baixo peso. A prevalência de óbito observada foi de $6,3 \%$ sendo significativa especialmente entre os com prematuridade moderada e extrema, os nascidos de mães adolescentes ou com mais idade de 40 anos, os com hipertemia, baixo peso, bradicardia e maiores tempo de internamento. Encontrou-se uma baixa frequência de hemocultura realizadas. Embora não tenha sido observado predomínio dos achados clínicos característicos da sepse como hipotermia, alterações do leucograma, contagem de plaquetas e níveis de PCR, os achados robustos de maior associação de extremo baixo peso ao nascer, hipertermia e taquipneia a maior frequência de óbito reforçam a qualidade dos dados obtidos.
\end{abstract}

Palavras-chave: Sepse neonatal; Fatores de risco; Óbito.

\begin{abstract}
Neonatal sepsis is one of the leading causes of death in newborns. Prior knowledge of risk factors is essential to prevent morbidity and mortality. This study aims to characterize the observed risk factors and their relationship with the occurrence of death in newborns diagnosed with sepsis. A cross-sectional study was carried out with the analysis of 712 participants hospitalized from September 2018 to June 2020. 410 neonates were included, with a higher proportion being males, born with artificial delivery and low birth weight. The prevalence of death observed was $6.3 \%$, occurring especially among those with moderate and extreme prematurity, those born to teenage mothers or mothers over forty, those with hyperthermia, low weight, bradycardia and longer hospital stays. There was a low frequency of blood cultures performed. Although there was no predominance of typical clinical findings of sepsis, such as hypothermia, changes in the leukogram, platelet count and CRP levels, the robust findings of a greater association of extreme low birth weight, hyperthermia and tachypnea to a higher frequency of death reinforce the quality of the data obtained.
\end{abstract}

Keywords: Neonatal sepsis; Risk factors; Death.

\section{Resumen}

La sepsis neonatal es una de las principales causas de muerte en los recién nacidos. El conocimiento previo de los factores de riesgo es fundamental para prevenir la morbimortalidad. Este estudio tiene como objetivo caracterizar los factores de riesgo observados y su relación con la ocurrencia de muerte en recién nacidos con diagnóstico de sepsis. Se realizó un estudio transversal con el análisis de 712 participantes hospitalizados desde septiembre de 2018 hasta junio de 2020. Se incluyeron 410 neonatos, con una mayor proporción del sexo masculino, nacidos con parto artificial y bajo peso al nacer. La prevalencia de óbito observada fue del 6,3\%, siendo significativa sobre todo entre aquellos 
con prematuridad moderada y extrema, los nacidos de madre adolescente y los mayores de 40 años, aquellos con hipertermia, bajo peso, bradicardia y estancias hospitalarias prolongadas. Hubo una baja frecuencia de hemocultivos realizados. Aunque no hubo predominio de hallazgos clínicos característicos de sepsis, como hipotermia, cambios en el leucograma, recuento de plaquetas y niveles de PCR, los hallazgos robustos de una mayor asociación de bajo peso extremo al nacer, hipertermia y taquipnea y una mayor frecuencia de muerte refuerzan la calidad de los datos obtenidos.

Palabras clave: Sepsis neonatal; Factores de riesgo; Muerte.

\section{Introdução}

A principal causa de morte em crianças com menos de 5 anos de idade em países subdesenvolvidos são as doenças infecciosas, e os recém-nascidos são os mais atingidos (Laxminarayan et al., 2016). Entre as infecções que acometem os neonatos, a sepse neonatal é a que atualmente representa uma das principais causas de morbidade e mortalidade (Kim et al., 2020). No Brasil, cerca de $60 \%$ da mortalidade infantil acontece no período neonatal, sendo a sepse neonatal uma das principais causas de óbito (Silva et al, 2015).

Conceitualmente, a sepse é caracterizada pelo aparecimento de dois ou mais sinais da Síndrome da Resposta Inflamatória Sistêmica (SIRS), sendo que um deles deve ser hipertermia/hipotermia e/ou alteração de leucócitos, concomitantemente à presença de quadro infeccioso confirmado ou suspeito (ILAS, 2019). De acordo com o tempo do aparecimento do quadro clínico, a sepse neonatal pode ser classificada em precoce, quando os sintomas aparecem nas primeiras 72 horas de vida, ou tardia, quando ocorre após as 72 horas de vida (Procianoy; R.S., \& Silveira, R.C. (2020); Kim et al., 2020).

Para os casos precoces, o recém-nascido (RN) adquire a sepse neonatal no período periparto, antes ou durante o parto. Logo, os microrganismos, na maioria das vezes, são do trato geniturinário materno. Os microrganismos gram-positivos representam, em média, 62\% dos agentes etiológicos da sepse neonatal precoce, sendo que, cerca de $43 \%$ desses são do microrganismo Streptococcus agalactiae, enquanto os gram-negativos representam $37 \%$, destes, dos quais $29 \%$ correspondem a Escherichia coli (Procianoy; R.S., \& Silveira, R.C,2020).

A ocorrência da sepse neonatal de início tardio em recém-nascidos deve-se a alguns fatores como: transmissão de patógenos do ambiente circundante após o parto, devido ao contato com profissionais de saúde ou cuidadores; manifestação tardia de infecção transmitida verticalmente e, a utilização de cateter intravascular ou outros procedimentos invasivos que rompem a integridade da mucosa (Singh et al.,2021).

O conhecimento prévio dos fatores de risco correlacionados a ocorrência da sepse neonatal são fundamentais para melhorar o cuidado em neonatologia especialmente em países em desenvolvimento e subdesenvolvidos (Kostlin-gille, et al.,2021). O diagnóstico rápido e preciso também é muito importante no desfecho da sepse neonatal.

Estudos recentes reforçam que metade das crianças com quadro de sepse falecem na primeira semana de choque refratário, sendo que, a maioria dessas vão a óbito antes mesmo da admissão na UTI, devido, principalmente, aos diagnósticos ineficazes (ILAS, 2019). O Global Burden of Disease (GBD) 2016/2017 estimou 1,3 milhões (IC 95\% 0,8 a 2,3) de casos incidentes anuais de sepse neonatal em todo o mundo, sendo que, 203.000 (IC 95\% 178.700 a 267.100) neonatos evoluem a óbito (James et al., 2018).

Clinicamente, sinais e sintomas presentes no RN, como instabilidade térmica, apneia, bradicardia, desconforto respiratório, hipoatividade, letargia e instabilidade hemodinâmica, quando não tem causa reconhecida, podem estar associados a sepse neonatal (Brasil, 2017). Dentre os fatores maternos, febre, trabalho de parto em gestação menor que 37 semanas, infecção do trato urinária (ITU) materna sem tratamento ou com este iniciado a menos de $72 \mathrm{~h}$, infecção materna por 
Streptococcus $B$ sem quimioprofilaxia intraparto, quando indicada, ruptura prematura de membranas amnióticas por tempo superior a 18 horas e corioamnionite são descritos como fatores de risco (Brasil, 2017).

Assim, a avaliação contínua sobre os fatores de risco para ocorrência da sepse neonatal e que aumentam a morbimortalidade entre os neonatos com infecções possibilita a implementação efetiva de estratégias preventivas e curativas (Almudeer; Alibrahim; Gosadi, 2020). Também, faz-se necessário estudos que analisem os fatores associados ao óbito neonatal em RNs com diagnóstico de sepse, na busca de compreender espaços para uma ação mais efetiva na redução da mortalidade por esta doença.

Este estudo tem como objetivo caracterizar os fatores de risco observados e sua relação com a ocorrência de óbito em recém-nascidos com diagnóstico de sepse em uma unidade de terapia intensiva neonatal de um hospital regional do interior da Bahia, Brasil.

\section{Metodologia}

Realizou-se um estudo transversal com análise de 712 participantes internados no período de setembro de 2018 a junho de 2020, em uma Unidade de Terapia Intensiva Neonatal (UTIN), localizada em Hospital de média e alta complexidade, localizada em Guanambi, município da região sudoeste da Bahia, Brasil. Esse hospital serve como referência para clínicas Médica, Cirúrgica, Pediátrica, Obstétrica, Internamento em UTI neonatal, UTI Adulto e Neurocirurgia, abrangendo 37 municípios, atendendo a uma população estimada em 586 mil pessoas (SESAB, 2020). O estudo foi aprovado no Comitê de Ética em Pesquisa da Universidade do Estado da Bahia (UNEB), parecer 4.463.864/2020, e na Comissão de Ensino e Pesquisa (COEP) do Hospital Geral de Guanambi.

Foram incluídos 410 recém nascidos, que apresentaram o diagnóstico de sepse neonatal, que iniciaram ou finalizaram o uso de antimicrobiano sistêmico durante o período de internação, em qualquer unidade do hospital. Os pacientes excluídos foram aqueles transferidos de outras instituições que já estavam em uso de antimicrobianos quando admitidos na UTIN, pacientes transferidos para outras unidades de saúde e aqueles que fizeram uso de antimicrobianos por mais de 30 dias.

Para a coleta de dados foi utilizado um formulário de elaboração dos autores, contendo informações de antecedentes maternos, história obstétrica, características clínicas e laboratoriais dos RNs, focando nos fatores de risco conhecidos para sepse neonatal e uso de antimicrobianos. Todos os dados foram obtidos a partir de prontuários dos RNs incluídos no estudo.

Alterações do equilíbrio térmico foram consideradas quando temperatura cutânea menor que $36,5^{\circ} \mathrm{C}$ (hipotermia) e maior que 37,5 $5^{\circ} \mathrm{C}$ (hipertermia) (Brasil, 2011; Brasil 2017). Bradicardia foi considerada quando a frequência cardíaca foi menor do que $100 \mathrm{bpm}$ e taquipneia, quando a frequência respiratória foi acima de $60 \mathrm{ipm}$ (Brasil, 2011). Leucocitose foi definida como contagem global de leucócitos $>25.000$ células $/ \mathrm{mm} 3$ e leucopenia considerada como contagem global de leucócitos $<5.000$ células $/ \mathrm{mm} 3$. Plaquetopenia foi definida como contagem global de plaquetas $<150.000$ células $/ \mathrm{mm} 3$. Os valores de PCR foram obtidos por aglutinação do látex. Neste método, o resultado negativo refere ausência de aglutinação indicando um teor de PCR inferior a $6 \mathrm{mg} / \mathrm{L}$. O resultado positivo indica presença de aglutinação indicando um teor de PCR igual ou superior a $6 \mathrm{mg} / \mathrm{L}$ Foram categorizados em três níveis: até $6 \mathrm{mg} / \mathrm{L}$ (referência), entre 6 e $12 \mathrm{mg} / \mathrm{L} \mathrm{e} \geq 24 \mathrm{mg} / \mathrm{L}$ (Brasil, 2017).

Os dados foram registrados em planilha eletrônica (Microsoft Excel ${ }^{\circledR}$, versão 2010), e as análises estatísticas complementares foram realizadas no pacote estatístico STATA®, versão 13.0. As variáveis utilizadas foram descritas com medidas de tendência central e dispersão, quando contínuas, e com medidas de frequência simples e relativa, quando categóricas. Para se comparar as variáveis quantitativas entre os grupos segundo a ocorrência de óbito utilizou-se o teste t para amostras não pareadas. O teste do qui-quadrado ou o teste exato de Fisher, quando indicado, foi utilizado para a mesma 
comparação, quando as exposições eram de natureza categórica. Modelos multivariados foram testados a partir da presença de variáveis com valor de $\mathrm{p}<0,200$ na análise univariada e/ou arcabouço teórico prévio na literatura. A regressão de Poisson com variância robusta foi utilizada para calcular os valores de razão de prevalências ajustados $\left(\mathrm{RP}_{\text {ajustado }}\right)$. Valores de $\mathrm{p}<0,05$ foram considerados significantes.

\section{Resultados}

Foram estudados 410 RNs admitidos na UTIN no período do estudo. As características demográficas e clínicas dos 410 recém-nascidos (RNs) avaliados estão descritas na Tabela 1.

Tabela 1 - Descrição das características relacionadas ao parto, nascimento, tempo de internamento e ocorrência de óbito dos 410 RNs internados na UTIN do HGG, entre setembro de 2018 e junho de 2020, Guanambi, Bahia.

\begin{tabular}{|c|c|}
\hline Variáveis & n $(\%)$ \\
\hline Sexo masculino & $217(53,0 \%)$ \\
\hline Sexo feminino & $193(47,0 \%)$ \\
\hline \multicolumn{2}{|l|}{ Tipos de parto } \\
\hline Cesariana & $240(58,6 \%)$ \\
\hline Vaginal & $167(40,7 \%)$ \\
\hline Sem informação & $3(0,7 \%)$ \\
\hline \multicolumn{2}{|l|}{ Classificação do RN ao nascer } \\
\hline Extremo baixo peso (Inferior a $1.000 \mathrm{~g}$ ) & $32(7,8 \%)$ \\
\hline Muito Baixo peso (Inferior a $1.500 \mathrm{~g}$ ) & $53(12,9 \%)$ \\
\hline Baixo peso (Inferior a $2.500 \mathrm{~g}$ ) & $179(43,7 \%)$ \\
\hline Dentro da normalidade (Acima de $2500 \mathrm{~g}$ ) & $146(35,6 \%)$ \\
\hline \multicolumn{2}{|l|}{ Peso ao nascer (em gramas) } \\
\hline Média (DP) & $2.213,9(833,3)$ \\
\hline Mediana (p25 - p75) & $2.142,0(1.630,0-2.805,0)$ \\
\hline \multicolumn{2}{|l|}{ Desfecho } \\
\hline Alta & $384(93,7 \%)$ \\
\hline Óbito & $26(6,3 \%)$ \\
\hline \multicolumn{2}{|l|}{ Tempo de internamento } \\
\hline Média (DP)* & $22,8(23,8)$ \\
\hline Mediana (p25 - p75) & $15,0(10,0-30,0)$ \\
\hline
\end{tabular}

RN: recém-nascido; DP: desvio-padrão; g: gramas; p25: percentil 25; p75: percentil 75. Fonte: Autores.

Observou-se predomínio de RNs masculinos, com via de parto artificial e baixo peso. A prevalência de óbito observada foi de $6,3 \%$.

Os antecedentes obstétricos dos RNs avaliados e sua associação com a ocorrência de óbito estão descritos na Tabela 2. 
Tabela 2- Antecedentes obstétricos dos pacientes internados na UTIN do HGG, município de Guanambi, Bahia, 2021.

\begin{tabular}{|c|c|c|c|c|}
\hline \multirow{3}{*}{ Variáveis } & \multirow{3}{*}{$\begin{array}{c}\text { Total } \\
\mathbf{N}(\%)\end{array}$} & \multicolumn{2}{|c|}{ Óbito } & \multirow{3}{*}{$\mathbf{P}$} \\
\hline & & Sim & Não & \\
\hline & & $\mathbf{N}(\%)$ & $\mathbf{N}(\%)$ & \\
\hline Idade materna & $\mathbf{N}=\mathbf{3 9 7}$ & & & \\
\hline Média (DP) & $27,5(7,1)$ & $27,2(8,6)$ & $27,6(7,0)$ & $0,823^{1}$ \\
\hline $19-39$ anos & $332(83,6 \%)$ & $18(5,42)$ & & $0,073^{2}$ \\
\hline Até 18 anos & $44(11 \%)$ & $5(11,4)$ & & \\
\hline 40 anos ou mais & $21(5,28 \%)$ & $3(14,3)$ & & \\
\hline Idade gestacional & $N=404$ & & & \\
\hline Média (DP) & $34,4(4.0)$ & $34,6(3,8)$ & $31,9(5,7)$ & $0,001^{1}$ \\
\hline Termo $(37-<42$ sem $)$ & $127(31,4)$ & $8(6,3)$ & & $<0,001^{3}$ \\
\hline Prematuro $(<37$ sem $)$ & $277(68,5)$ & $18(6,5)$ & & \\
\hline $32-<37$ sem & $195(70,4)$ & $5(2,6)$ & & \\
\hline $28-<32$ sem & $56(20,2)$ & $6(10,7)$ & & \\
\hline$<28 \mathrm{sem}$ & $26(9,4)$ & $7(26,9)$ & & \\
\hline Tempo de duração do parto & $N=299$ & & & $>0,999^{2}$ \\
\hline$<12$ horas & $214(71,6)$ & $16(7,5)$ & & \\
\hline 12-24 horas & $27(9,0)$ & $2(7,4)$ & & \\
\hline$>24$ horas & $58(19,4)$ & $4(6,9)$ & & \\
\hline Bolsa rota & $N=369$ & & & $0,929^{4}$ \\
\hline Rompimento precoce & $159(43,1)$ & $8(5,0)$ & & \\
\hline Durante o trabalho de parto & $210(56,9)$ & $11(5,2)$ & & \\
\hline Infecção do Trato urinário & $N=404$ & & & $0,246^{2}$ \\
\hline Sim & $115(28,5)$ & $4(3,5)$ & & \\
\hline Não & $289(71,5)$ & $20(6,9)$ & & \\
\hline Utilização prévia de ATM & $N=404$ & & & $0,305^{4}$ \\
\hline Sim & $140(34,7)$ & $6(4,3)$ & & \\
\hline Não & $264(65,3)$ & $18(6,8)$ & & \\
\hline
\end{tabular}

DP: desvio-padrão; ATM: antimicrobiano; ${ }^{1}$ teste t não pareado; ${ }^{2}$ teste exato de Fisher; ${ }^{3}$ teste do qui-quadrado de tendência linear; ${ }^{4}$ teste do qui-quadrado. Fonte: Autores

Não houve totalidade de dados para estas variáveis, com perda variando de 27,1\% a 1,5\% das observações. Observouse mortalidade significativa e crescente entre os RNs com prematuridade moderada e extrema $(\mathrm{p}<0,001)$. Tendência a maior mortalidade foi observada entre as mães adolescentes e àquelas com idade $\geq$ a 40 anos ( $\mathrm{p}=0,073)$ 
A Tabela 3 mostra as características clínicas do RNs correspondente a primeira avaliação médica do internamento na UTIP e algumas características laboratoriais entre os RNs avaliados e segundo ocorrência de óbito. Dos 410 pacientes, 178 $(43,4 \%)$, realizaram o exame de hemocultura, sendo que desses, somente dois microrganismos foram isolados (Escherichia coli e Staphylococcus aureus).

Tabela 3- Diagnósticos mais frequentes e exames laboratoriais realizados para os pacientes internados na UTIN do Hospital Geral de Guanambi, Guanambi, Bahia.

\begin{tabular}{|c|c|c|c|c|c|}
\hline \multirow{3}{*}{ Variáveis } & & \multirow{3}{*}{$\begin{array}{l}\text { Total } \\
\mathbf{N}(\%)\end{array}$} & \multicolumn{2}{|l|}{ Óbito } & \multirow{3}{*}{$\mathbf{P}$} \\
\hline & & & Sim & Não & \\
\hline & & & $\mathbf{N}(\%)$ & $\mathbf{N}(\%)$ & \\
\hline Temperatura $\left({ }^{\circ} \mathrm{C}\right)$ & & $\mathrm{N}=407$ & & & \\
\hline Média (DP) & & $36,2(0,8)$ & $36,2(0,7)$ & $35,8(1,1)$ & $0,010^{1}$ \\
\hline $36,5-37,5$ & & $136(33,4)$ & $2(1,5)$ & & $0,003^{2}$ \\
\hline$>37,5$ & & $9(2,2)$ & $2(22,2)$ & & \\
\hline$<36,5$ & & $262(64,4)$ & $21(8,0)$ & & \\
\hline Frequência Cardíaca (bpm) & & $\mathrm{N}=\mathbf{4 1 0}$ & & & \\
\hline Média (DP) & & $140,3(16,2)$ & $140,2(15,7)$ & $141,3(23,6)$ & $0,745^{1}$ \\
\hline Bradicardia ausente & & $408(99,5)$ & $25(6,1)$ & & $0,123^{2}$ \\
\hline Bradicardia presente & & $2(0,5)$ & $1(50,0)$ & & \\
\hline Frequência Respiratória (ipm) & & $\mathrm{N}=\mathbf{4 0 7}$ & & & \\
\hline Média (DP) & & $51,4(13,4)$ & $51,5(13,2)$ & $57,3(35,9)$ & $0,348^{3}$ \\
\hline Taquipneia ausente & & $330(81,1)$ & $17(5,2)$ & & $0,186^{4}$ \\
\hline Taquipneia presente & & $77(18,9)$ & $7(9,1)$ & & \\
\hline Leucócitos (céls/mm3 x 1000) & & $\mathrm{N}=\mathbf{4 0 0}$ & & & \\
\hline Média (DP) & & $12,14(0,81)$ & $12,02(0,81)$ & $14,3(0,77)$ & $0,206^{1}$ \\
\hline $5.000-25.000$ & & $374(93,5)$ & $19(5,1)$ & & $0,164^{2}$ \\
\hline$<5.000$ & & $13(3,3)$ & $1(7,7)$ & & \\
\hline$>25.000$ & & $13(3,3)$ & $2(15,4)$ & & \\
\hline Plaquetas (céls/mm3 x 100.000) & $\mathrm{N}=\mathbf{4 0 0}$ & & & & \\
\hline Média (DP) & $265,0(96,8)$ & $265,8(97,6)$ & $250,6(80,8)$ & & $0,474^{1}$ \\
\hline Plaquetopenia ausente & $376(94,0)$ & $21(5,6)$ & & & $>0,999^{2}$ \\
\hline Plaquetopenia presente & $24(6,0)$ & $1(4,2)$ & & & \\
\hline $\begin{array}{l}\text { Proteína-C Reativa qualitativo } \\
(\mathrm{mg} / \mathrm{l})\end{array}$ & $\mathrm{N}=404$ & & & & $0,401^{2}$ \\
\hline Até 6 & $283(69,7)$ & $18(6,4)$ & & & \\
\hline $12-24$ & $66(16,3)$ & $2(3,0)$ & & & \\
\hline
\end{tabular}


${ }^{\circ} \mathrm{C}$ : graus Celsius; DP: desvio-padrão; bpm: batimentos por minuto; ipm: incursões por minuto; céls: células; ${ }^{1}$ teste t não pareado; ${ }^{2}$ teste exato de Fisher; ${ }^{3}$ teste t não pareado com variâncias desiguais; ${ }^{4}$ teste do qui-quadrado. Fonte: Autores

Observou-se que a presença de instabilidade térmica foi associada a maior ocorrência de óbitos, especialmente, para os RNs com hipertermia (22,2\% de óbitos neste grupo). A presença de bradicardia foi pouco representativa no grupo estudado, embora $50 \%(1 / 2)$ dos RNs com esta condição tenha apresentado o desfecho óbito (tabela 3 ).

Para os exames avaliados, na presença de leucocitose observou-se um percentual de óbito 3x maior $(15,4 \%$ vs. 5,1\%) quando comparado a faixa considerada adequada, sem associação estatística $(\mathrm{p}=0,164)$ na análise univariada. Achado similar foi observado para a dosagem de PCR, para a qual não foi observada associação.

Em relação ao peso ao nascer, observou-se um crescimento na prevalência de óbito à medida que os RNs tinham menores valores. Especificamente, foram observados, respectivamente, mortalidade de 5,5\%, 2,2\%, 7,6\% e 31,3\% para os que nasceram com mais de $2.500 \mathrm{~g}$, entre $1.500 \mathrm{~g}$ e $2.500 \mathrm{~g}$, entre $1.500 \mathrm{e} 1.000 \mathrm{~g}$ e abaixo de $1.000 \mathrm{~g}\left(\mathrm{p}_{\text {tendência }}<0,001\right)$.

Para a presença de prematuridade, considerada como variável dicotômica, não foi observado diferenças, sendo a frequência de óbito de $6,3 \%$, entre os RNs nascidos a termo, e 6,5\% para aqueles prematuros ( $\mathrm{p}=0,940)$. Contudo, maior gravidade de prematuridade se associou a maior ocorrência de óbito (ptendência<0,001), como mostrado na Tabela 4 , com RPbruta de 4,27 (IC95\%:1,70 - 10,76). 
Tabela 4 - Razões de prevalência brutas e ajustadas para a ocorrência de óbito segundo variáveis da história obstétrica e características clínicas e laboratoriais dos 410 RNs avaliados, internados na UTIN do Hospital Geral de Guanambi, Guanambi, Bahia.

\begin{tabular}{lc}
\hline Variável & $\mathbf{R P}_{\text {bruta }}(\mathbf{I C 9 5 \%})$ \\
\hline Tipo de parto & \\
Natural & 1,0 \\
Artificial & $0,70(0,33-1,46)$
\end{tabular}

Idade Gestacional (semanas)

$$
\begin{aligned}
& \text { Termo }(37 \mid-42) \\
& \text { PT moderado/tardio }(32 \mid-37) \\
& \text { PT muito prematuro }(28 \mid-32)
\end{aligned}
$$

PT extremo $(<28)$

Peso ao Nascer (g)

Acima de 2.500

Entre $2.500-1.500$

Entre $1.500-1.000$

Inferior a 1.000

Idade Materna (anos)

$19-39$

$<18$

$\geq 40$

\section{ITU Materna}

Ausente

Presente

\section{Bolsa Rota}

Durante o trabalho de parto

Rompimento precoce

Tempo de internamento (dias)

$1-7$

8-15

$>15$
1,0

$0,41(0,14-1,22)$

$1,70(0,62-4,68)$

$4,27(1,70-10,76)$

1,0

$0,41(0,13-1,33)$

$1,38(0,43-4,39)$

$5,70(2,41-13,32)$

1,0

$2,10(0,82-5,37)$

$2,63(0,84-8,25)$

1,0

$1,99(0,70-5,69)$

1,0

$0,96(0,40-2,33)$

1,0

$0,05(0,02-0,16)$

$0,07(0,03-0,17)$
$<0,001$

RP $_{\text {ajustada }}$ (IC95\%)

(Modelo Saturado)

RP ${ }_{\text {ajustada }}$ (IC95\%)

(Modelo Final)

0,336
(1)

1,0

$0,71(0,24-2,05)$

$0,87(0,11-6,79)$

$0,39(0,05-2,85)$

$<0,001$

1,0

1,0

$1,16(0,44-3,02)$

NS

$2,98(0,69-12,92)$

NS

$19,40(2,59-145,10)$

$9,30(4,10-21,12)$

0,073

1,0

$2,91(0,85-9,96)$

$1,57(0,55-4,50)$
$<0,001$

1,0

$0,16(0,03-0,77)$

$0,07(0,02-0,24)$
1,0

$0,12(0,03-0,47)$

$0,08(0,03-0,22)$ 


\section{Bradicardia}

Ausente

Presente

Alteração Leucocitária

Ausente

Leucopenia

Leucocitose

0,123

1,0

$8,16(1,94-34,34)$

1,0

$1,51(0,22-10,49)$

$3,03(0,79-11,68)$
1,0

$0,10(0,01-1,22)$

0,164

1,0

$0,82(0,35-1,91)$

$4,27(0,66-27,65)$

PT: pré-termo; ITU: infecção do trato urinário; RP: Razão de Prevalência; IC0=95\%: intervalo de confiança de 95\%; NS: Não significante. Fonte: Autores.

\section{Discussão}

No presente estudo, realizado em um hospital de média e alta complexidade do interior da Bahia, observou-se que os RNs que foram tratados na UTI neonatal para sepse neonatal eram, em sua maioria, do sexo masculino, nascidos de parto artificial, com baixo peso ao nascer, prematuros e que se apresentaram, clinicamente, com hipotermia e com leucograma, contagem de plaquetas e níveis de PCR dentro da normalidade. Adicionalmente, observou-se óbito precoce, até o $7^{\circ}$ dia de vida, na maioria dos RNs que não sobreviveram, e foram identificados como fatores associados ao óbito, o peso de nascimento abaixo de $1.000 \mathrm{~g}$, a presença de hipertermia e taquipneia.

o Ministério da Saúde ressalta que recém-nascidos do sexo masculino apresentam duas a seis vezes mais chances de apresentarem sepse neonatal precoce que meninas. Supõem-se que isso ocorra devido à deficiência de receptores para interleucina-1 no sexo masculino, o que poderia predispor à infecção (Brasil, 2011). Apesar dessa hipótese e da predominância de meninos entre àqueles que foram tratados como tendo sepse neonatal, o sexo do RN não se associou ao óbito no presente estudo.

O parto cesáreo, apesar da não exposição dos recém nascidos as bactérias vaginais e fecais, também é considerado um fator de risco para ocorrência da sepse, uma vez que, RNs nascidos por esta via, frequentemente, passam por internação hospitalar prolongada e início tardio da amamentação além da possibilidade de ocorrer transmissão placentária (Ferrieri; Wallen, 2018; Mugadza et al.,2018; Bager et al., 2010). Assim como o sexo do RN, este fator também não impactou na mortalidade.

No presente estudo, foi possível observar a relação entre o baixo peso e a presença de sepse neonatal, bem como com a maior frequência de óbito. Especificamente, foi encontrado uma prevalência de óbito mais de nove vezes, quando comparados aos RNs nascidos com $2.500 \mathrm{~g}$ ou mais. A literatura aponta como uma das justificativas para que isso ocorra, a disfunção imunológica e ausência de anticorpos IgG maternos adquiridos por via transplacentária, devido desenvolvimento precoce desses recém-nascidos (Burga-Montoya et al., 2019). Mesmo em crianças que não desenvolvem sepse neonatal, o extremo baixo peso é um conhecido fator de risco para óbito neonatal (Brasil, 2011)

É consensual na literatura de que o baixo peso ao nascer é um fator para o aumento das infecções. Em um estudo realizado por Stoll e colaboradores, em 2010, estes autores demonstraram que, para cada 1000 RNs, a incidência de sepse neonatal precoce relatada foi de 0,57 entre àqueles com mais de 2.500 gramas, e 10,96, em neonatos com peso ao nascer entre 401-1500 gramas (Stoll et. al, 2010). Similarmente, a sepse neonatal tardia também é inversamente proporcional ao peso no nascer, quanto menor o peso maior a incidência de infecções (Dong; Speer, 2015). 
A prematuridade, em conjunto com o baixo peso ao nascer, são os principais fatores de risco para o desenvolvimento da sepse neonatal. Isso foi verificado no presente estudo, pois entre os RNs internados com sepse neonatal, mais de $65 \%$ deles tinham as duas condições. O risco de apresentar sepse entre os recém-nascidos prematuros e de baixo peso ao nascer é de três a dez vezes maior que os recém-nascidos termo e com peso adequado no nascimento para desenvolvimento de sepse neonatal (Shane et al.,2017). Embora não tenha comparado essas variáveis entre os RNs nascidos na unidade hospitalar em que se realizou o presente trabalho, foi possível descrever uma associação 9,3 vezes superior de óbito entre os RNs com peso ao nascer inferior a $1.000 \mathrm{~g}$, confirmando os achados da literatura, entre os neonatos estudados.

Estudos realizados no Brasil também demonstram que a prematuridade é um fator de risco para o desenvolvimento da sepse neonatal, como por exemplo estudos realizados na cidade de Montes Claros, interior de Minas Gerais, no qual 60\% dos RNs internados, em 2017, em hospital escola, eram pré-termos e também dados de uma instituição de referência estadual na assistência materno-infantil do Rio Grande do Norte, na qual se demonstrou que 78\% dos nascimentos eram pré-termos (Dos Santos et al., 2019 e Santos 2014).

Foi observado que a presença de taquipneia, embora não tenha sido a condição respiratória mais frequente, foi relevante entre os recém-nascidos do estudo, constituindo fator associado a maior frequência de óbito. A síndrome do desconforto respiratório é comum em recém-nascidos prematuros especialmente por terem desenvolvimento pulmonar incompleto, e tem se mostrado muito frequente, também em recém-nascidos a termo, com uma taxa de incidência relativamente alta 5\%-10\% (Reuter; Moser, 2014; Mcpherson; Wambach, 2018). Adicionalmente, quando o desconforto respiratório vem acompanhado com outros sintomas como letargia, apneia, febre e taquicardia, deve-se considerar a possibilidade de sepse neonatal (Chowdhury et al.,2019). Embora, o fato de a coleta de dados ter sido em fonte secundária (prontuários), o que limita a qualidade do dado obtido, o presente trabalho observou que, tanto taquipneia quanto hipertermia foram fatores independentes associados a maior prevalência de óbito, o que reforça o já descrito na literatura e torna os RNs com estas condições como prioritárias para a atenção multiprofissional precoce e intensiva (Brasil, 2011; Chowdhury et al.,2019). Devido a semelhança dos sintomas é necessário avaliar cautelosamente os pacientes com suspeita de sepse para que dessa forma, os pacientes não sejam tratados com antimicrobianos de forma desnecessária. Embora não tenha sido o foco deste trabalho, todos os RNs estudados, até por terem apresentado suspeita de sepse neonatal, utilizaram antibióticos.

Em relação aos antecedentes obstétricos, para a idade materna abaixo dos 18 anos e acima dos 40 anos, observou-se uma maior ocorrência de óbito neonatal, contudo, não se antevê significante, nos modelos multivariados utilizados. A literatura considera essas condições de idade materna como gestações de alto risco, o que aumenta a probabilidade de prematuridade e baixo peso ao nascer, fatores classicamente associados a maior ocorrência de sepse neonatal e mortalidade (Shane et al.,2017; Dong; Speer, 2014; Brasil, 2011).

A ruptura precoce da membrana também é considerada um fator de risco para o desenvolvimento da sepse neonatal (Procianoy \& Silveira, 2020). No presente estudo, cerca de 43\% dos neonatos apresentaram esse achado, que não foi associado a maior frequência de óbito. Quando ocorre a ruptura precoce da membrana, a incidência de sepse aumenta (Rathore et al.,2020). Considerando a utilização prévia de antimicrobianos durante a gestação, 35\% das gestantes utilizaram antimicrobianos, mas esse uso não se mostrou relevante para indicar maior mortalidade.

A infecção do trato urinário (ITU) durante a gravidez está associada ao maior risco de sepse neonatal. A probabilidade de mulheres com infecção urinária darem à luz recém-nascidos baixo peso e prematuros são bem maiores, sendo que esses são os principais fatores que desencadeiam a sepse neonatal (Wendel et al., 2002). Além disso, a ITU durante a gravidez também pode estar associada a um aumento na mortalidade neonatal e septicemias por Gram positivos (Alexander et al., 1999). Ademais, metanálise recente, realizada por Bayih e colaboradores em 2021, realizada com um total de 36.016 neonatos 
incluídos em 27 estudos concluiu que os recém-nascidos de mães que tiveram infecção do trato urinário no pré-natal apresentaram risco 3,55 vezes maior (IC95\%: 2,04- 5,06) de desenvolver sepse neonatal em comparação com os recémnascidos de mães que não tiveram infecção do trato urinário pré-natal (Bayih et al., 2021). O rastreamento de gestantes com Infecção do trato urinário e o tratamento são ações fundamentais para que sejam evitadas complicações (Bayih et al., 2021).

Observou-se uma baixa positividade das hemoculturas realizadas entre os RNs estudados. É um desafio o diagnóstico da sepse por meio da hemocultura. A confirmação da sepse por meio da cultura é de aproximadamente $0,4-0,8$ por 1000 recémnascidos a termo em países de alta renda (Bekker et al.,2014).No presente estudo, a taxa de positividade foi de 11,2/1000 hemoculturas realizadas. Aproximadamente 6 a 16 recém-nascidos recebem tratamento para sepse com cultura negativa na ausência de hemocultura positiva, o que contribui cada vez mais para o aumento do consumo de antimicrobianos (Klingenberg et al.,2018). Este fato reforça a necessidade de melhorias no processo de diagnóstico laboratorial e no uso racional dos antimicrobianos, bem como no descalonamento posterior. A razão para o alto número de hemocultura negativa ainda não é clara, abrindo questionamentos sobre o tratamento eficiente e os programas de manejo de antimicrobianos (Klingenberg et al.,2018).

Apesar da hemocultura ser considerada padrão ouro na identificação da sepse alguns pontos são levantados para justificar o grande número de hemoculturas negativas, podendo-se citar níveis baixos de bacteremia, pequenos volumes de sangue obtidos para realização da hemocultura, o tratamento com antimicrobianos maternos antes ou durante o parto, ou bactérias, fungos ou vírus fastidiosos o que pode mascarar o resultado. (Villar et al, 2006; Buttery, 2002; Wirtschafter et al., 2011; Klingenberg et al.,2018).

$\mathrm{O}$ uso limitado da microbiologia contribui para a indicação definitiva limitada e o alto consumo de antimicrobianos especialmente em países pobres e em desenvolvimento. Assim, outras formas de diagnósticos devem ser utilizadas de maneira complementar. Atualmente existem outros tipos de métodos utilizados de forma complementar para o diagnóstico da sepse como os biomarcadores e métodos moleculares baseados na reação em cadeia da polimerase. Outros adjuvantes potenciais futuros promissores são a metabolômica (BROMIKER et al., 2020).

Neste trabalho, foram avaliados o comportamento da proteína-C reativa (PCR), do leucograma e da contagem plaquetária. A dosagem da PCR é um exame barato, acessível e que vem se mostrado bastante promissor no diagnóstico complementar da sepse neonatal, uma vez que, a secreção da proteína $\mathrm{C}$ tem início de 4 a 6 horas após estimulação, e o pico ocorre em 36 horas (Bloos; Reinhart, 2014). Alterações destes exames oscilaram em torno de 6\% dos neonatos, para o leucograma e a contagem de plaquetas, e de $30 \%$ para elevação do PCR. Adicionalmente, nenhum destes marcadores foram associados a ocorrência de óbito.

Estudo elaborado por Bunduki e Adu-sarkodie em 2020, com pacientes neonatais internados em três hospitais de Butembo, na República Democrática do Congo, demostrou que dos 228 neonatos triados para sepse, 69 (30,3\%) tiveram hemocultura positiva, sendo que desses, $94(41,2 \%)$ apresentaram PCR positivo. A sensibilidade, especificidade, valores preditivos positivos e negativos da PCR foram $95,7 \%, 82,4 \%, 70,2 \%$ e $97,8 \%$, respectivamente. Concluindo, portanto, que a proteína $\mathrm{C}$ reativa é eficiente no diagnóstico da sepse neonatal, podendo ser útil especialmente em países pobres em que o exame de hemocultura não é disponível ou enquanto o exame da hemocultura não for disponibilizado (Bunduki; Adu-Sarkodie, 2020).

Outro estudo realizado com duzentas e oito amostras detectou por meio da hemocultura somente cinco amostras positivas. Já, a PCR positivou em 91 amostras das 203 amostras que não mostraram crescimento bacteriano na hemocultura, confirmando mais uma vez que a PCR em tempo real é extremamente importante para o diagnóstico da sepse neonatal (Oeser et al.,2020). 
Algumas limitações estão presentes no estudo. O uso de dados secundários de prontuários não permitiu clareza em algumas variáveis coletadas e outras não foram possíveis de serem operacionalizadas. Adicionalmente, o fato de não ter sido coletado o número de neutrófilos, dado que a neutropenia é um preditor mais fidedigno de sepse neonatal, pode ter mascarado o papel do laboratório na predição de óbito (Procianoy \& Silveira, 2020). Também pode ser citado o fato de que muitos dos RNs podem ter sido tratados de maneira equivocada como tendo sepse neonatal, o que explica os bons índices de mortalidade observados, dado que a literatura costuma referir taxas maiores em unidades de média e alta complexidade. Apesar disso, os achados robustos de maior associação de extremo baixo peso ao nascer, hipertermia e taquipneia a maior frequência de óbito reforçam a qualidade dos dados obtidos.

\section{Conclusão}

Observou-se, primeiramente, que os RNs que foram tratados na UTI neonatal para sepse neonatal eram, em sua maioria, do sexo masculino, nascidos de parto artificial, com baixo peso ao nascer, prematuros, fatores descritos como de risco para sepse neonatal. Em segundo lugar, não foi observado predomínio de achados clínicos descritos como fatores de risco para óbito por sepse neonatal, pois não houve predomínio de hipotermia, alterações do leucograma, contagem de plaquetas e níveis de PCR entre os neonatos estudados. Em terceiro lugar, encontrou-se uma baixa frequência de positividade a hemocultura. Por fim, observou-se óbito precoce, até o $7^{\circ}$ dia de vida, na maioria dos RNs que não sobreviveram, e foram identificados como fatores associados ao óbito, o peso de nascimento abaixo de $1.000 \mathrm{~g}$, a presença de hipertermia e taquipneia.

\section{Referências}

Alexander, J. M., McIntire, D. M., \& Leveno, K. J. (1999). Chorioamnionitis and the prognosis for term infants. Obstetrics \& Gynecology, 94(2), 274-278.

Almudeer, AH, Alibrahim, MA, \& Gosadi, IM (2020). Epidemiologia e fatores de risco associados à sepse neonatal precoce no sul de KSA. Jornal de Ciências Médicas da Universidade de Taibah, 15 (6), 509-514.

Bager, P., Simonsen, J., Ethelberg, S., \& Frisch, M. (2010). Cesarean delivery and risk of intestinal bacterial infection. The Journal of infectious diseases, 201(6), 898-902.

Bayih, W. A., Ayalew, M. Y., Chanie, E. S., Abate, B. B., Alemayehu, S. A., Belay, D. M., ... \& Alemu, A. Y. (2021). The burden of neonatal sepsis and its association with antenatal urinary tract infection and intra-partum fever among admitted neonates in Ethiopia: A systematic review and metaanalysis. Heliyon, 7(2), e06121.

Bekker, V., Bijlsma, M. W., van de Beek, D., Kuijpers, T. W., \& van der Ende, A. (2014). Incidence of invasive group B streptococcal disease and pathogen genotype distribution in newborn babies in the Netherlands over 25 years: a nationwide surveillance study. The Lancet Infectious Diseases, 14(11), 1083-1089.

BLOOS, F.; REINHART, K. Rapid diagnosis of sepsis. Virulence, v. 5, n. 1, p. 154-160, 2014.

Brasil. (2011). Secretaria de Atenção à Saúde. Departamento de Ações Programáticas e Estratégicas. Atenção à saúde do recém-nascido: guia para os profissionais de saúde / Ministério da Saúde, Secretaria de Atenção à Saúde, Departamento de Ações Programáticas e Estratégicas. Brasília: Ministério da Saúde,

Brasil. (2017). Gerência de Vigilância e Monitoramento em Serviços de Saúde (GVIMS). Critérios diagnósticos de infecção associada à assistência à saúde: neonatologia. Brasília: Ministério da Saúde.

Bromiker, R., Elron, E., \& Klinger, G. (2020). Do Neonatal Infections Require a Positive Blood Culture?. American journal of perinatology, 37(S 02), S18S21.

Bunduki, G. K., \& Adu-Sarkodie, Y. (2020). The usefulness of C-reactive protein as a biomarker in predicting neonatal sepsis in a sub-Saharan African region. BMC research notes, 13(1), 1-5.

Burga-Montoya, G., Luna-Muñoz, C., \& López, L. C. (2019). Factores de riesgo asociados a sepsis neonatal temprana en prematuros de un Hospital Nacional Docente Madre Niño, 2017. Revista de la Facultad de Medicina Humana, 19(3), 35-42.

Buttery, J. P.(2002). Blood cultures in newborns and children: optimising an everyday test. Archives of Disease in Childhood-Fetal and Neonatal Edition, v. 87, n. 1 .

Chowdhury, N., Giles, B. L., \& Dell, S. D. (2019). Full-term neonatal respiratory distress and chronic lung disease. Pediatric annals, 48(4), e175-e181. 
Dong, Y., \& Speer, C. P. (2015). Late-onset neonatal sepsis: recent developments. Archives of Disease in Childhood-Fetal and Neonatal Edition, 100(3), F257-F263.

Santos, L. A. N., de Jesus Nunes, J. P., Souza, L. A. P., de Almeida, B. C. R., Rodrigues, C. A. O., Ruas, S. J. S., ... \& de Pinho, L. (2019). Prevalência de sepse em neonatos internados em um hospital escola. Revista Renome, 8(1), 58-66.

Ferrieri P, Wallen LD (2018). Sepse e Meningite do Recém-nascido. In: Gleason CA, Juul SE, editores. Doenças de Avery do Recém-nascido. 10 edição. Filadélfia, PA: Elsivier.

Instituto Latino Americano de Sepse (2019). Campanha de sobrevivência a sepse protocolo clínico pediátrico.

James, SL, Abate, D., Abate, KH, Abay, SM, Abbafati, C., Abbasi, N., ... \& Briggs, AM (2018). Incidência global, regional e nacional, prevalência e anos vividos com incapacidade para 354 doenças e lesões para 195 países e territórios, 1990-2017: uma análise sistemática para o Estudo de Carga Global de Doenças 2017. The Lancet, 392 (10159), 1789-1858.

Kim, F.; Polin, R. A.; Hooven, T. A (2020). Neonatal sepsis. BMJ, 371.

Klingenberg, C., Kornelisse, R. F., Buonocore, G., Maier, R. F., \& Stocker, M. (2018). Culture-Negative Early-Onset Neonatal Sepsis - At the Crossroad Between Efficient Sepsis Care and Antimicrobial Stewardship. Frontiers in pediatrics, 6, 285. https://doi.org/10.3389/fped.2018.00285.

Köstlin-Gille, N., Härtel, C., Haug, C., Göpel, W., Zemlin, M., Müller, A., ... \& Gille, C. (2021). Epidemiologia da sepse neonatal precoce e tardia em recémnascidos de muito baixo peso: dados da Rede Neonatal Alemã. The Pediatric Infectious Disease Journal , 40 (3), 255-259.

Laxminarayan R, Matsoso P, Pant S, Brower C, Røttingen JA, Klugman K, Davies S (2016). Access to effective antimicrobials: a worldwide challenge. Lancet.

McPherson C, Wambach JÁ (2018). Prevention and Treatment of Respiratory Distress Syndrome in Preterm Neonates. Neonatal Netw. 1;37(3):169-177.

Mugadza, G., Zvinavashe, M., Gumbo, F. Z., \& Pedersen, B. S. (2018). Early breastfeeding initiation and incidence of neonatal sepsis in Chipinge District Zimbabwe. Int J Contemp Pediatr, 5,1 .

Oeser, C., Pond, M., Butcher, P., Bedford Russell, A., Henneke, P., Laing, K., ... \& Harris, K. (2020). PCR for the detection of pathogens in neonatal early onset sepsis. PLoS One, 15(1), e0226817.

Procianoy, R. S., \& Silveira, R. C. (2020). The challenges of neonatal sepsis management. Jornal de pediatria, 96, 80-86.

Rathore, H., Rahman, A. J., Salman, M., Nasir, M., \& Sherali, S. (2020). Frequency of Early-onset Neonatal Sepsis Following Prolonged Rupture of Membranes. Cureus, 12(2).

Reuter, S., Moser, C., \& Baack, M. (2014). Respiratory distress in the newborn. Pediatrics in review, 35(10), 417.

Santos, A. P. D. S., Silva, M. D. L. C. D., Souza, N. L. D., Mota, G. M., \& França, D. F. D. (2014). Nursing diagnoses of newborns with sepsis in a Neonatal Intensive Care Unit. Revista latino-americana de enfermagem, 22, 255-261.

Shane, AL, Sánchez, PJ, \& Stoll, BJ (2017). Sepse neonatal. A lanceta , 390 (10104), 1770-1780.

Secretaria d Saúde do Estado da Bahia (2020). Hospital Geral de Guanambi. Saúde .ba.gov.br. http://www.saude.ba.gov.br/hospital/hospital-regional-deguanambi/

Silva, SMR, Motta, GDCPD, Nunes, CR, Schardosim, JM, \& Cunha, MLCD (2015). Sepse neonatal tardia em recém-nascidos pré-termo com peso ao nascer inferior a 1.500 g. Revista Gaúcha de Enfermagem , 36, 84-89.

Singh, M.; Alsaleem, M.; Grey, C. P.(2021). Neonatal Sepsis. StatPearls.

Stoll, B. J., Hansen, N. I., Bell, E. F., Shankaran, S., Laptook, A. R., Walsh, M. C., Hale, E. C., Newman, N. S., Schibler, K., Carlo, W. A., Kennedy, K. A., Poindexter, B. B., Finer, N. N., Ehrenkranz, R. A., Duara, S., Sánchez, P. J., O'Shea, T. M., Goldberg, R. N., Van Meurs, K. P., Faix, R. G., ... Eunice Kennedy Shriver National Institute of Child Health and Human Development Neonatal Research Network (2010). Neonatal outcomes of extremely preterm infants from the NICHD Neonatal Research Network. Pediatrics,

Villar, J., Valladares, E., Wojdyla, D., Zavaleta, N., Carroli, G., Velazco, A., ... \& Acosta, A. (2006). Caesarean delivery rates and pregnancy outcomes: the 2005 WHO global survey on maternal and perinatal health in Latin America. The Lancet, 367(9525), 1819-1829.

Wendel G.D., Leveno K.J, Sánchez P.J., Jackson G.L., McIntire D.D., Siegel J. D. (2002). Prevention of neonatal group B streptococcal disease: A combined intrapartum and neonatal protocol. Am J Obstet Gynecol. 2002 Apr;186(4):618-26.

Wirtschafter, D. D., Padilla, G., Suh, O., Wan, K., Trupp, D., \& Fayard, E. S. (2011). Antibiotic use for presumed neonatally acquired infections far exceeds that for central line-associated blood stream infections: an exploratory critique. Journal of Perinatology, 31(8), 514-518. 